\title{
Defective ALK5 signaling in the neural crest leads to increased postmigratory neural crest cell apoptosis and severe outflow tract defects
}

\author{
Jikui Wang1, Andre Nagy ${ }^{1}$, Jonas Larsson², Marek Dudas' ${ }^{1}$, Henry M Sucov ${ }^{3}$ \\ and Vesa Kaartinen*1
}

\begin{abstract}
Address: ${ }^{1}$ Developmental Biology Program, The Saban Research Institute of Childrens Hospital Los Angeles, Departments of Pathology and Surgery, Keck School of Medicine, University of Southern California, Los Angeles, CA 90027, USA, ${ }^{2}$ Molecular Medicine and Gene Therapy, Institute of Laboratory Medicine and Department of Medicine, Lund University Hospital, 22100 Lund, Sweden and ${ }^{3}$ Institute for Genetic Medicine, Keck School of Medicine University of Southern California, Los Angeles, CA 90033, USA

Email: Jikui Wang - jikwang@chla.usc.edu; Andre Nagy - anagy@chla.usc.edu; Jonas Larsson - Jonas.Larsson@med.lu.se; Marek Dudas - mdudas@chla.usc.edu; Henry M Sucov - sucov@usc.edu; Vesa Kaartinen* - vkaartinen@chla.usc.edu

* Corresponding author
\end{abstract}

Published: 0I November 2006

BMC Developmental Biology 2006, 6:5 I doi: $10.1|186 / 147|-2|3 X-6-5|$
Received: 19 July 2006

Accepted: 0 I November 2006

This article is available from: http://www.biomedcentral.com/|47|-2/3X/6/5 I

(c) 2006 Wang et al; licensee BioMed Central Ltd.

This is an Open Access article distributed under the terms of the Creative Commons Attribution License (http://creativecommons.org/licenses/by/2.0), which permits unrestricted use, distribution, and reproduction in any medium, provided the original work is properly cited.

\begin{abstract}
Background: Congenital cardiovascular diseases are the most common form of birth defects in humans. A substantial portion of these defects has been associated with inappropriate induction, migration, differentiation and patterning of pluripotent cardiac neural crest stem cells. While TGF$\beta$-superfamily signaling has been strongly implicated in neural crest cell development, the detailed molecular signaling mechanisms in vivo are still poorly understood.
\end{abstract}

Results: We deleted the TGF- $\beta$ type I receptor Alk5 specifically in the mouse neural crest cell lineage. Failure in signaling via ALK5 leads to severe cardiovascular and pharyngeal defects, including inappropriate remodeling of pharyngeal arch arteries, abnormal aortic sac development, failure in pharyngeal organ migration and persistent truncus arteriosus. While ALK5 is not required for neural crest cell migration, our results demonstrate that it plays an important role in the survival of post-migratory cardiac neural crest cells.

Conclusion: Our results demonstrate that ALK5-mediated signaling in neural crest cells plays an essential cell-autonomous role in the pharyngeal and cardiac outflow tract development.

\section{Background}

A considerable percentage of cardiac birth defects is caused by a failure in normal migration, differentiation or patterning of the cardiac neural crest (CNC). This subset of pluripotent neural crest stem cells forms in the dorsal aspect of the neural tube at the level of the mid-otic placode to the third somite [1]. Subsequently cardiac neural crest cells (CNCCs) delaminate, undergo a phenotypic transformation from an epithelial to mesenchymal cell type, and migrate latero-ventrally into the $3^{\text {rd }}, 4^{\text {th }}$ and $6^{\text {th }}$ pharyngeal arch arteries (PAAs), where they contribute to the formation of the smooth muscle cell layer of endothelial structures derived from the aortic arch arteries [1-3]. A subset of CNCCs continues to migrate deeper into the aortic sac to form the aortico-pulmonary septum; a vital 
structure, which separates the pulmonary trunk from the aorta [4].

An indispensable role of CNCCs in the development of the cardiac outflow tract was originally demonstrated by pioneering studies of Kirby and coworkers [1], who showed that ablation of the $\mathrm{CNC}$ in the chick led to severe outflow tract (OFT) defects including persistent truncus arteriosus (PTA), mispatterning of the great vessels and outflow tract mal-alignments [5]. Early migratory CNCCs have been shown to retain a considerable degree of plasticity and their fate is largely controlled by instructional signals from local environments into which NCCs migrate [6]. Several recent studies have indicated that members of the TGF- $\beta$ superfamily, i.e., TGF- $\beta$ s and BMPs are likely candidates to provide some of these signals. Mice deficient in TGF- $\beta 2$ display fourth aortic arch artery defects [7], while neural crest cell specific abrogation of TGF- $\beta$ type II receptor ( $\mathrm{Tgfbr} 2)$ results in interruption of the aortic arch and PTA $[8,9]$. BMPs 6 and -7 are required for proper formation of the outflow tract cushions [10], while BMP type II receptor is needed for proper development of the conotruncal ridges [11]. Moreover, neural crest-specific deletion of the BMP type I receptors Alk2 and Alk3 has been shown to lead to defective aortico-pulmonary septation, among other cardiac defects $[12,13]$.

TGF- $\beta$ subfamily ligands signal via a receptor complex composed of two type II receptors and two type I receptors $[14,15]$. Ligand binding leads to phosphorylation and activation of type I receptors, which, in turn, phosphorylate and activate a specific set of downstream signaling molecules called Smads. In general terms, TGF- $\beta$ s bind to the TGF- $\beta$ type II receptor (TGF $\beta$ RII) and TGF- $\beta$ type I receptor (ALK5) activating TGF- $\beta$ Smads ( 2 and 3 ), while BMPs bind to the BMP type II receptor and type I receptors ALK2, -3, or 6, activating BMP Smads (1, 5 and 8). However, it is likely that these signaling interactions are more complex in vivo, possibly allowing formation of heterotetrameric complexes composed of different type II and type I receptors [16]. In addition, recent studies have identified novel TGF- $\beta$-related ligands, which can bind to entire different combinations of receptors. For instance, growth and differentiation factors (GDFs) 8 and 9 can bind to Activin type II receptor and ALK5 to activate TGF- $\beta$ Smads $[17,18]$. Therefore, we hypothesized that deletion of Alk5 in a specific cell lineage should reveal phenotypes which cannot be seen in comparable mutants lacking Tgfbr2. Indeed, we recently showed that neural crest cell specific Alk5 mutants display a unique spectrum of craniofacial developmental defects, e.g., cleft snout and severe mandibular hypoplasia [19]; these phenotypes were not seen in corresponding Tgfbr2 mutants [20]. To determine, whether ALK5 would also mediate unique non-redundant signaling events in cardiac neural crest cells, we focused on cardiac and pharyngeal phenotypes of mouse embryos lacking Alk5 specifically in neural crest cells. We discovered that in Alk5/Wnt1-Cre mutants, pharyngeal organs (thymus and parathyroid) fail to migrate appropriately. Moreover, the mutant embryos display severe aortic sac and pharyngeal arch artery defects, and failed aortico-pulmonary septation leading to PTA. Our data further suggest that at least some of these abnormal detected phenotypes result from a dramatic increase in apoptosis of postmigratory cardiac neural crest cells. These phenotypes differ remarkably from those seen in corresponding Tgfbr2 mutants, suggesting that ALK5 mediates a wider spectrum of signaling events than its classical binding partner TGF$\beta R I I$ in cardiac neural crest cells during cardiac and pharyngeal development.

\section{Results \\ Persistent truncus arteriosus and abnormal large vessels in mice lacking Alk5 in cardiac NCCs}

To inactivate Alk5 in cardiac NCCs, mice homozygous for the floxed Alk5 allele (Alk5Flox/Flox) [21] were crossed with transgenic Wnt1-Cre mice [22], which were also heterozygous for the Alk5 knockout allele $\left(A l k 5^{K O}\right)$ allele. The resulting mice heterozygous for the Alk5 $5^{F l o x}$ and Alk5KO alleles, which also carried the Wnt1-Cre transgene, had the Alk5 gene specifically inactivated in NCCs (herein termed Alk5/Wnt1-Cre), while the littermates with remaining allelic combinations were phenotypically normal and served as controls (Alk5 $5^{\mathrm{Flox} /+}$, Alk5 $\mathrm{KO} /+;$ Wht1-Cre). When embryos were harvested during the last day of gestation, an expected number $(25 \%)$ of Alk5/Wnt1-Cre mutants were recovered. However, all mutant offspring died either during the birth or during the first post-natal hours.

To determine, if ALK5-mediated TGF- $\beta$-signaling had a role in development of the OFT and large vessels of the aortic arch, we performed casting dye experiments on E17 embryos (Fig. 1A-D). In wild-type embryos (Fig. 1A), the aorta was clearly separated from the pulmonary trunk, and the right brachiocephalic, left carotid and left subclavian arteries branched directly off the aortic arch. In contrast, Alk5/Wnt1Cre mutant embryos consistently displayed a single prominent arterial trunk (Fig. 1C-D), while corresponding Tgfbr 2 mutant embryos (Fig. 1B) displayed interrupted aortic arch, as reported earlier [8]. Approximately $40 \%$ of the Alk5 mutants had a right-sided outflow tract, with the retroesophageal arch connecting to the descending aorta and to the left subclavian artery. The carotid arteries originated either from a common bud located in the ventral side of the ascending arch, or from separate adjacent sites, as verified by serial sectioning (Fig. $1 \mathrm{M}-\mathrm{P})$. The remaining mutants displayed a left-sided aortic arch, where the right carotid arteries originated from the right lateral aspect of the ascending trunk, while the left carotid arteries budded from the ventral or right ven- 
tral aspects of the trunk (Fig. 1I-L). Both right and left subclavian arteries consistently originated from the descending part of the aortic arch. Similarly, in all mutants both left and right pulmonary arteries always branched out from the common arterial trunk. To conclude, Alk5/Wnt1-Cre mutants consistently displayed PTA, which differed significantly from the characteristic interrupted aortic arch phenotype seen in Tgfbr2/Wnt1-Cre mutants $[8,9]$.

\section{Abnormal patterning of the pharyngeal arch arteries and aortic sac in Alk5/Wnt I Cre mutants}

During cardiovascular development, the PAAs undergo a complex set of sequential asymmetric remodeling steps resulting in the left-sided aortic arch. To determine, whether ALK5-mediated signaling was involved in remodeling of PAAs, we performed intracardiac India ink injections at different developmental stages. While at E10, Alk5/Wnt1-Cre mutants did not show obvious differences in the PAAs, abnormal remodeling became obvious in mutants a day later at E11 (Fig. 2). The controls displayed the well-formed $3^{\text {rd }}, 4^{\text {th }}$ and $6^{\text {th }}$ PAAs. Moreover, the carotid duct (the dorsal aorta between the $3^{\text {rd }}$ and $4^{\text {th }}$ PAAs) was already regressing as demonstrated by the reduced size (Fig. 2A). In Alk5/Wnt1-Cre mutants, the $3^{\text {rd }}$ and $4^{\text {th }}$ pairs of PAAs were bilaterally hypoplastic, whereas the $6^{\text {th }}$ pair of PAAs was notably hyperplastic (Fig. 2B). Furthermore, the carotid duct was remarkably large, when compared to controls. While the controls displayed an interruption of the carotid duct at E12 and E13 as expected (Fig. 2C), the mutants demonstrated an uncharacteristic break of the dorsal aorta between the $4^{\text {th }}$ and $6^{\text {th }}$ pairs of PAAs (Fig. 2D).

Around E11.5, the aortic sac normally forms a distinctive T-shaped structure, as seen in frontal sections of the control sample in Fig. 3(A,C). Subsequently, the right horn of this structure transforms into the prospective brachiocephalic artery, while the left horn together with the left

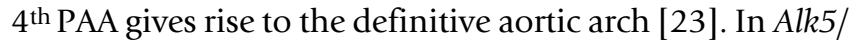
Wnt1-Cre mutants, the T-shaped aortic sac failed to form (Fig. 3B,D). Instead, the truncus bifurcated to a left and right arm, which further branched to the PAAs, particularly to the predominant pair of $6^{\text {th }}$ PAAs (Fig. 3B,D). The observed phenotype is consistent with the absence or severe hypoplasia of structures derived from the aortic sac in late stage embryos (E17), e.g., the missing brachiocephalic artery and severe shortening of the ascending truncus as shown in the Figure 1.

\section{Cardiac NCCs deficient in Alk5 can populate the outflow tract}

Next we used the R26R lineage-tracing assay to determine whether CNCCs could appropriately populate the outflow tract region. Briefly, Alk5Flox/Flox mice were crossed with the ROSA26 Cre reporter mice, and subsequently Alk5Flox/Flox;R26R(+/+) females were crossed with Alk5KO/ WT;Wnt1-Cre males. The resulting embryos had the NClineage permanently labeled with $\beta$-galactosidase expression, and displayed identical phenotypes to those obtained without the R26R reporter. Staining of embryos for $\beta$-galactosidase at E8-E11 did not reveal detectable differences in NCC migration between mutants and controls (data not shown). Similarly, serial transverse sectioning of whole mount embryos (E10-E12) and subsequent analysis of positively stained cells in the OFT region demonstrated that CNCCs deficient in Alk5 were capable of populating the PAAs, aortic sac and conotruncal ridges at a level comparable to that of controls (Fig 4). To conclude, the observed phenotypes in Alk5/Wnt1-Cre mutants were certainly not due to defective migration of CNCCs to the pharyngeal and outflow tract regions.

\section{Aortic sac and aortico-pulmonary septal defects in Alk5/ Wnt I Cre mutant embryos}

Septation of the outflow tract lumen begins in a cranialto-caudal direction, starting distally in the aortic sac and proceeding toward the heart [24]. Initially, the condensed mesenchyme derived from the $\mathrm{NC}$ forms in the base of the aortic sac between the origins of $4^{\text {th }}$ and $6^{\text {th }}$ PAAs. Subsequently, two prongs of the developing aortico-pulmonary (AP) septum extend into the truncal cushions and the aortico-pulmonary septation complex crosses the aortic sac cranially. In ink-injected control embryos at E11.5, a characteristic conotruncal transition separating the truncus and conus could be seen as a twisted configuration, resulting from a change in orientation of the truncal and conal cushions (Fig. 5). In contrast, in Alk5/Wnt1-Cre mutants the outflow tract appeared unusually straight, failing to demonstrate the distinct conotruncal transition (Fig. $5 \mathrm{~B}, \mathrm{D})$. This assay also clearly showed a dramatic reduction in the size of the aortic sac. Histological analysis of control samples displayed the characteristic rotation of the aortic sac and truncal OFT at the level where the AP septation takes place and verified the presence of the distinctive condensed AP-septal mesenchyme, which gradually divided the OFT to the aorta and the pulmonary trunk (asterisks in Fig. 6A). R26R lineage tracing showed that this tissue is derived from the $\mathrm{NC}$, while immunostaining for $\alpha$-SMA showed differentiation into smooth muscle (Fig 6B). In Alk5/Wnt1-Cre mutants the characteristic rotation of the aortic sac and truncal OFT fails to take place (Fig. 6G-L), and a properly formed AP-septum was not detectable (Fig. 6G,H). R26R lineage tracing demonstrated that the defects were not due to failure of NCCs to reach the OFT region. NC-derived cells around the abnomally bifurcated aortic sac, the abnormally large sixth PAAs and the truncus demonstrated strong $\alpha \mathrm{SMA}$ staining (Fig. 6H,J,L). Recently, we showed that the NCspecific mutants of the related type I receptor, Alk2, dis- 
Control

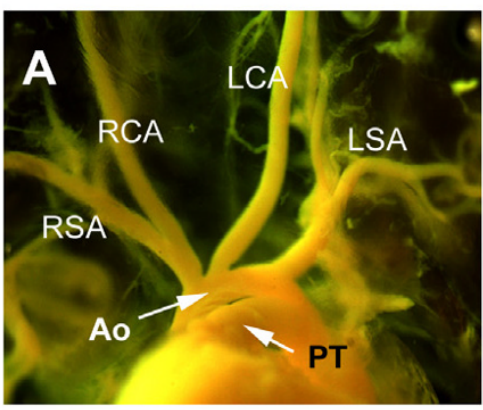

Alk5/Wnt1-Cre (RS)

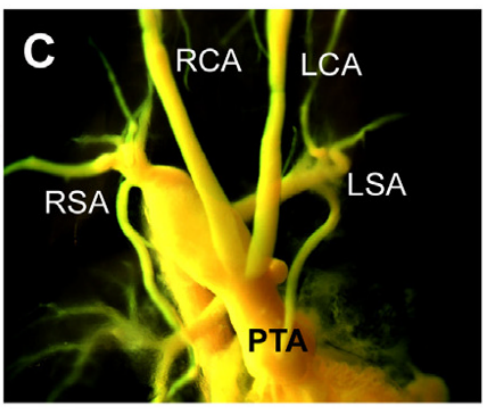

Tbr2/Wnt1-Cre

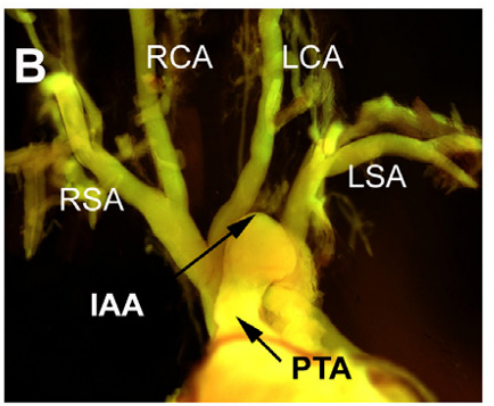

Alk5/Wnt1-Cre (LS)

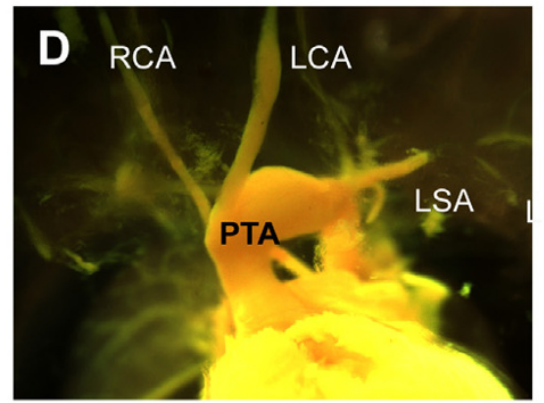

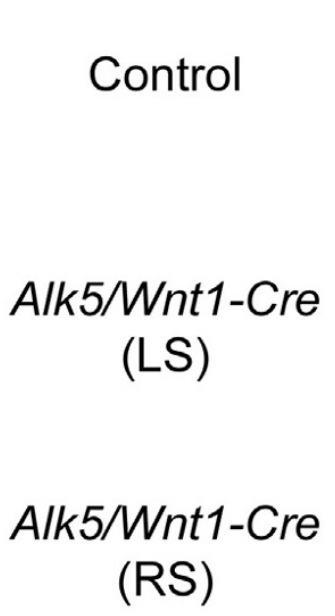
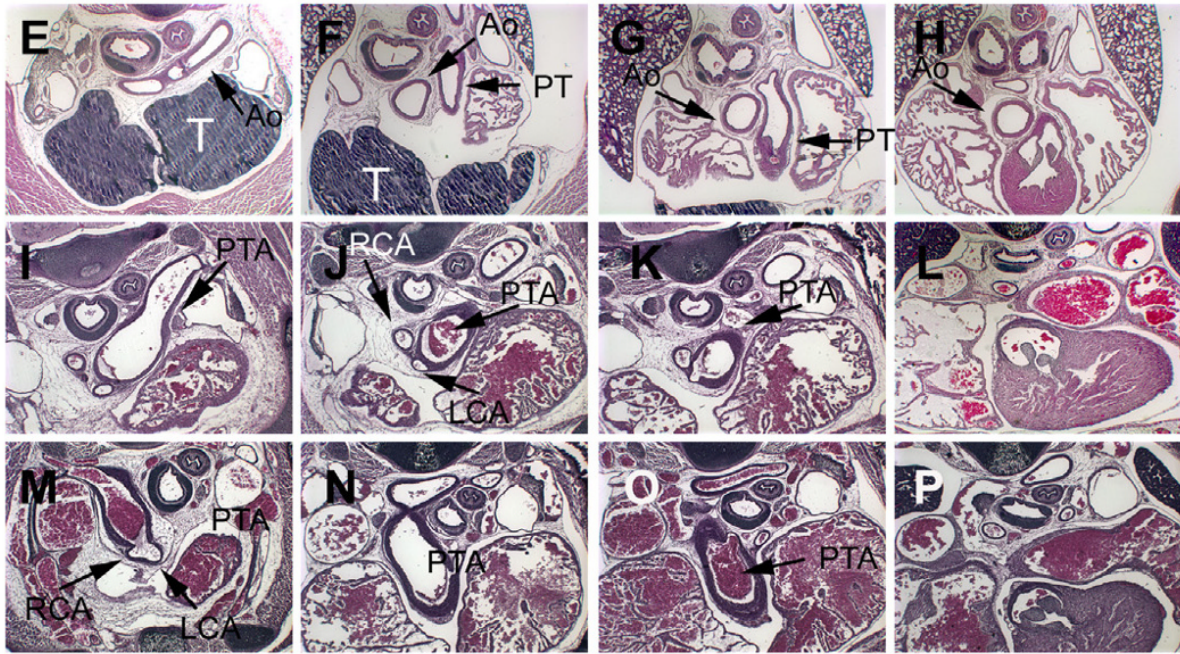

Figure I

Abrogation of Alk5 in neural crest cells leads to persistent truncus arteriosus type $\mathbf{A} 2$. A-D, Casting-dye analysis of OFT morphogenesis at EI7.0. Control (A), Tgfbr2/Wnt I-Cre mutant [8] (B) demonstrating the PTA type A4 (= truncus arteriosus with interrupted aortic arch [30]) and Alk5/Wnt l-Cre mutants demonstrating the right-sided (C) and left-sided (D) arches of the truncus. E-P, Histological cross-sections on four different levels (rostral to caudal) at EI7.0. In a control (E-H), the ascending aorta (Ao) and pulmonary trunk (PT) are separated by the conotruncal septum. In Alk5/Wnt I-Cre mutants (I-P) the conotruncal septum fails to form, and either left-sided (I-L) or right-sided (M-P) aortic arch can be seen. Aberrant branching of carotid arteries from the truncus has been illustrated by black arrows ( and $M)$. Ao, aorta; PT, pulmonary trunk; RSA, right subclavian artery; RCA, right carotid artery; LCA; left carotid artery; LSA, left subclavian artery; IAA, interrupted aortic arch; PTA, persistent truncus arteriosus. 


\section{Control}
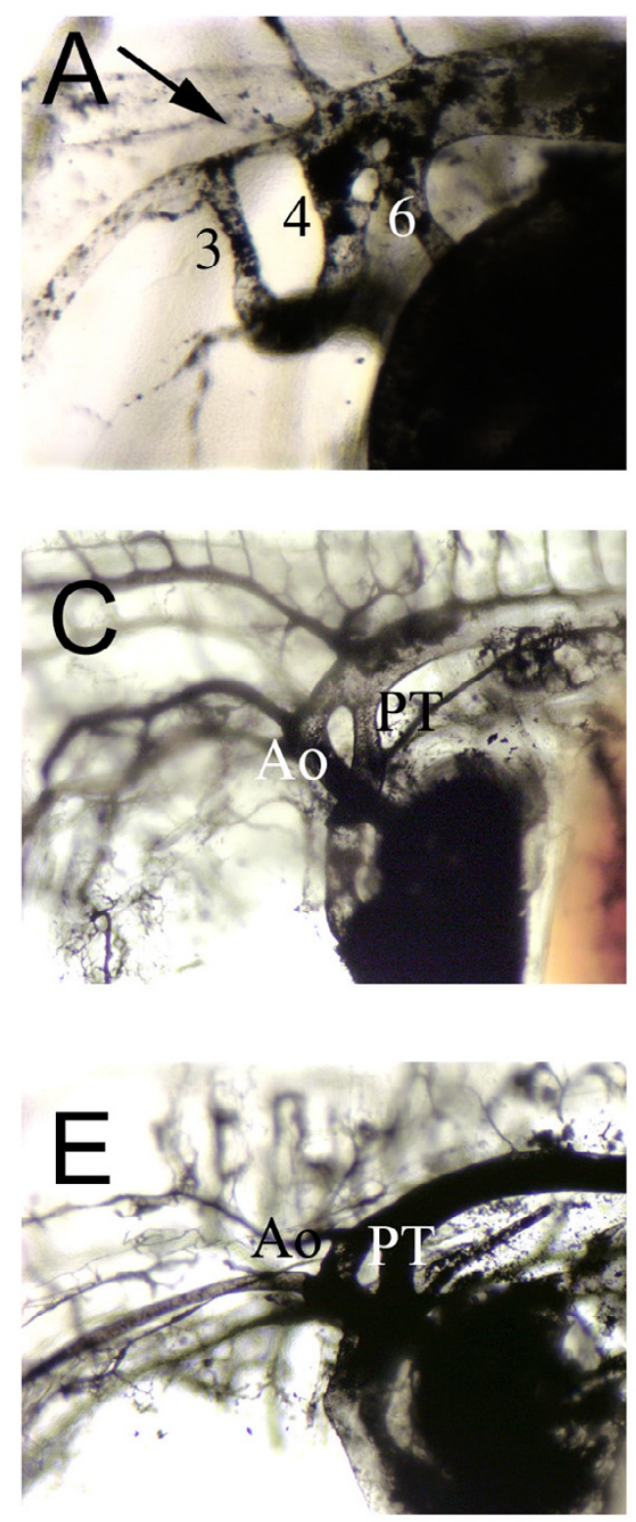

\section{Alk5/Wnt1-Cre}
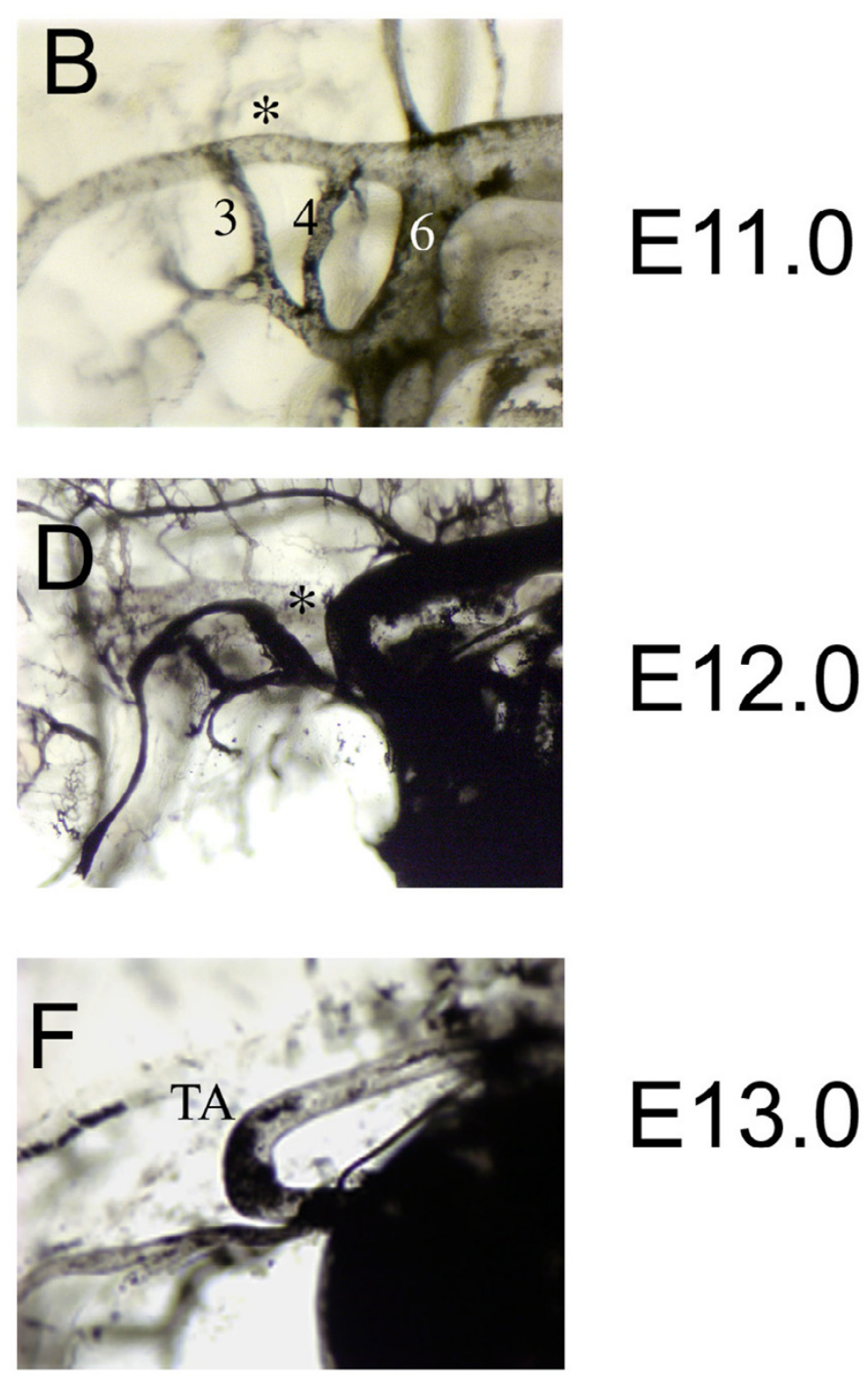

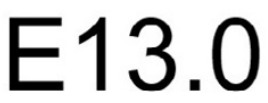

\section{Figure 2}

Abnormal patterning of the PAAs in Alk5/Wnt I-Cre mutants. Left lateral view after intracardiac ink injections to visualize the developing PAAs at EII.0 (A,B), EI2.0 (C, D) and EI3.0 (E, F) in controls (A, C, E) and Alk5/Wnt I-Cre mutants (B, D, F). Arrow in $A$ points to the regressing carotid duct. Asterisk in $B$ depicts the corresponding structure in the mutant with no signs of regression. Asterisk in $D$ illustrates the aberrant regression of the dorsal aorta between the $4^{\text {th }}$ and $6^{\text {th }}$ PAAs. PT, pulmonary trunk; Ao, Aorta; TA, truncus arteriosus.

play PTA as well [12]. In Alk2/Wnt1-Cre mutants, the rotation of the aortic sac and truncal OFT failed to occur (Fig. $6 \mathrm{M}-\mathrm{R}$ ) as seen in Alk5/Wnt1-Cre mutants. However, in
Alk2 mutants the $6^{\text {th }}$ pair of the PAAs was grossly hypoplastic, and while the Alk2/Wnt1-Cre mutants displayed a noticeable amount of septal tissue between the $4^{\text {th }}$ and $6^{\text {th }}$ 
Control

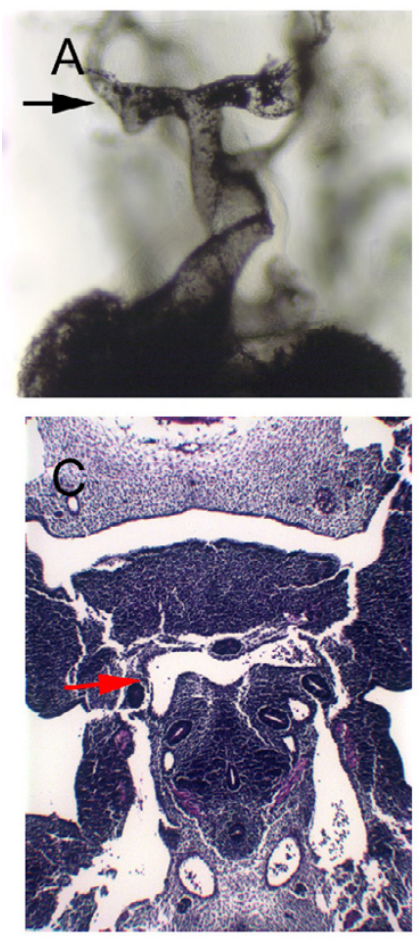

Alk5/Wnt1-Cre
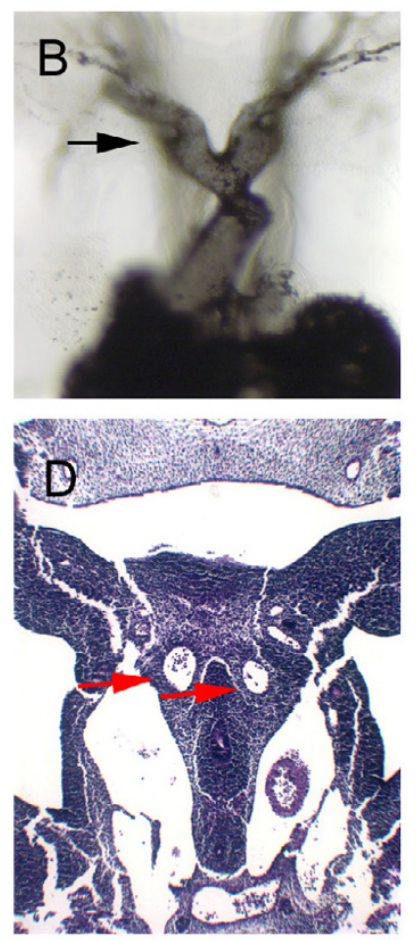

\section{Figure 3}

Abnormal Aortic Sac in Alk5/Wnt I-Cre mutants. Alk5/ Wnt l-Cre mutants (B, D) fail to form the typical T-shaped structure of the aortic sac seen in controls at EII.5. (A, C). $A-B$, frontal image of ink-injected embryos; $C-D$, frontal sections (H\&E staining). Arrows in $A$ and $B$ point to the level of section shown in $C$ and $D$ (red arrows in $C$ and $D$ point to the aortic sac of the control and mutant, respectively).

PAAs (Fig. 6M,N), the condensed septal mesenchyme lacking Alk2 failed to extend the prongs into the truncal cushions and to form the AP septum. Concurrently, the $6^{\text {th }}$ PAAs were losing their patency, which may have further contributed to the failed AP septation (Fig. 6M,O,Q). While CNCCs managed to migrate to the aortic sac and the truncal cushion level (Fig. 6N,P,R), immunostaining for $\alpha \mathrm{SMA}$ appeared much weaker when compared to controls and Alk5 mutants, implying that ALK2-mediated signaling is involved in smooth muscle cell differentiation as previously suggested [12]. To conclude, while both Alk2 and Alk5 mutants demonstrate a failure in both the rotation of the aortic sac and the truncal OFT, and in the formation of the AP septum, the pathogenetic mechanisms behind these defects appear remarkably different.

\section{Alk5/Wntl-Cre mutants display increased apoptosis of post-migratory neural crest cells}

As described above, Alk5/Wnt1-Cre mutants displayed an inadequate amount of AP-septal tissue in the base of the aortic sac between the origins of $4^{\text {th }}$ and $6^{\text {th }}$ PAAs. To analyze whether this phenotype resulted either from defective CNCC proliferation or inappropriate apoptosis, we used BrdU and TUNEL staining, respectively. While CNCC proliferation was not affected in Alk5 mutants (data not shown), we could detect a dramatic increase in the number of TUNEL positive cells in tissues surrounding the aortic sac including the site where the AP-septum forms (Fig. 7A-C). Dual staining for lacZ and TUNEL positive cells demonstrated that these cells were postmigratory CNCCs; this phenotype was already clearly detectable at E10.5. These results were confirmed by using immunostaining for cleaved caspase-3, another marker for apoptosis (Fig. 7I,J). In the chick, apoptotic neural crest-derived cells have also been found at the sites, where the prongs of the AP septum penetrate into the OFT cushion mesenchyme $[25,26]$. Thus, we compared apoptosis patterns also on the more proximal level, but found no detectable differences at E11.0 between Alk5/Wnt1-Cre mutants and controls (Fig. 7D,E). Unlike in Alk5/Wnt1-Cre mutant embryos, increased apoptosis of NC-derived cells is not responsible for the observed defects in the OFT septation in corresponding Alk2 mutants (Fig. 7C,E).

To conclude, our results suggest that in Alk5/Wnt1-Cre mutants a noticeable increase in apoptosis coincides with the abnormal patterning of the PAAs and the aortic sac, and with the failed AP-septation. These data support a specific role for ALK5 signaling, either directly or indirectly, in CNCC survival, since a similar apoptosis of NCderived cells is not seen in Tgfbr2/Wnt1-Cre mutants [8,9].

\section{Pharyngeal organs fail to migrate in Alk5/Wnt I-Cre mutants}

In addition to the cardiac OFT, development of pharyngeal organs, i.e., the parathyroid glands and the thymus was also abnormal in Alk5/Wnt1-Cre mutants (see Figs. 1 and 8). Normally the thymus develops from the third pharyngeal pouch endoderm and migrates caudally to its final location in the superior mediastinum as seen in controls at E14 (Fig. 8A,B). In contrast, the thymic primordia of the Alk5 mutant littermates failed to descend caudally, and were located bilaterally in the neck region, where they were surrounded by neural crest-derived mesenchyme (Fig. 8D,E). The fate determination assay demonstrated that the thymic primordia were equally populated by NCCs both in controls and Alk5 mutants (Fig. 8B,E). Likewise the parathyroid glands failed to migrate normally in Alk5/Wnt1-Cre mutants. During normal development, the parathyroids first migrate in association with the thymic primordia, until they reach the thyroids in the neck region 


\section{Control}
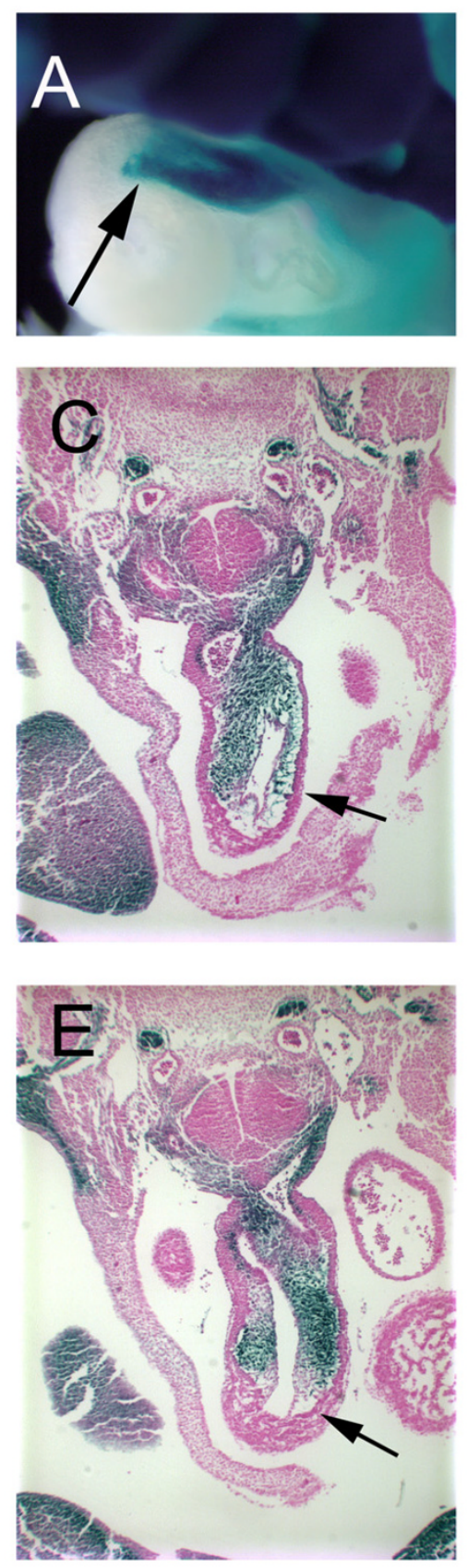

\section{Alk5/Wnt1-Cre}
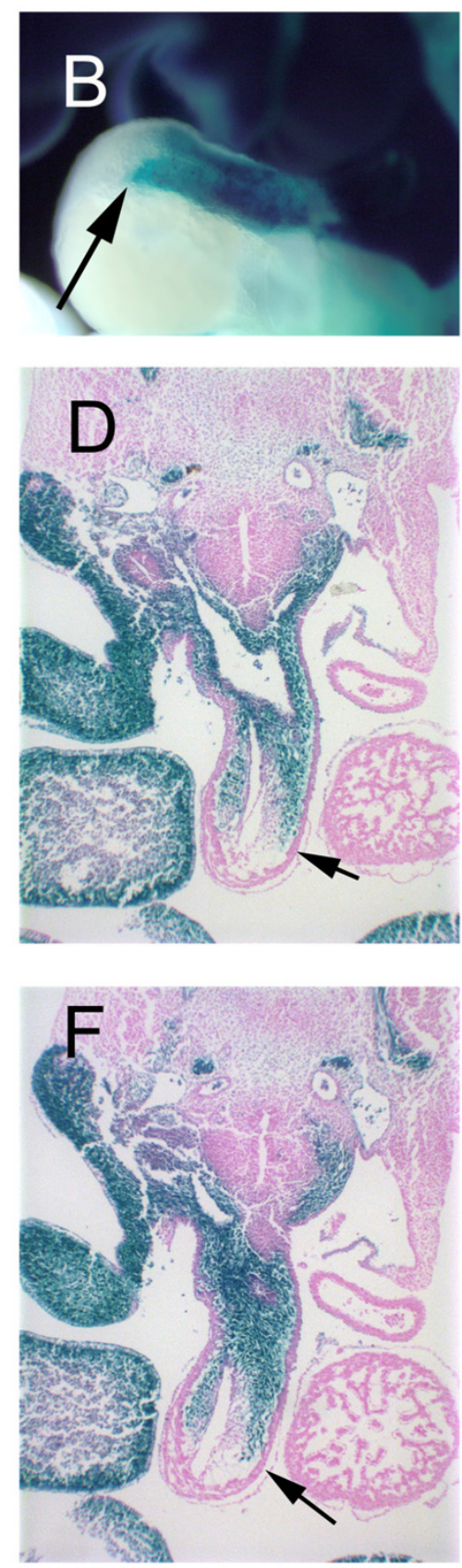

\section{Figure 4}

Normal cardiac NCC migration in Alk5/Wnt l-Cre mutants. The OFT of controls (A, C, E) and Alk5/Wntl-Cre mutants $(B, D, F)$ display similar staining patterns when analyzed using the $R 26 R$ lineage tracing assay at EI I.0. A-B, whole mount staining (left lateral image); C-F, transverse sections on the level of the $4^{\text {th }}(C, D)$ and $6^{\text {th }}(E, F)$ PAAs. Arrows (A-F) point to the most proximal location staining positive for the $\beta$-galactosidase activity. 


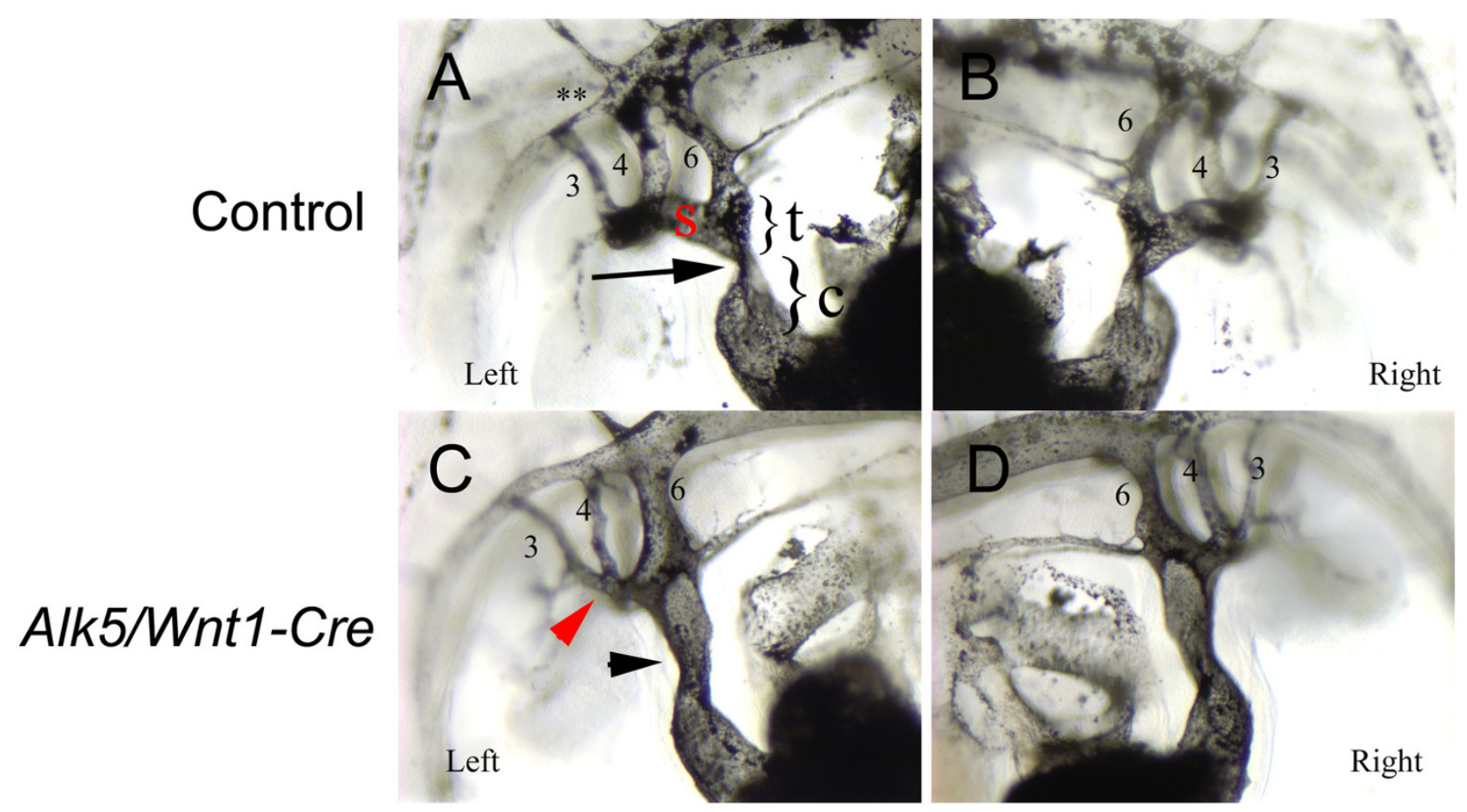

Figure 5

The truncal OFT fails to rotate in Alk5/Wnt I-Cre mutants. Left (A, C) and right (B, D) lateral images of ink-injected control (A-B) and mutant (C-D) embryos at EI I.5 demonstrate the abnormally straight OFT in mutants lacking the typical conotruncal transition (black arrow in A vs. black arrowhead in $C$ ) seen in control. Red arrowhead (C) points to the abnormally shaped aortic sac. Red "s", aortic sac; $t$, truncus; c, conus.

as seen in Fig 8C. In Alk5/Wnt1-Cre mutants, the parathyroids remained associated with the thymic primordia, and despite this abnormal rostral location, expression of parathyroid hormone was indistinguishable between Alk5 mutants and controls at E14 (Fig. 8C,F). To conclude, the observed pharyngeal organ phenotypes were also in striking contrast to those seen in Tgfbr2/Wnt1-Cre mutants $[8,9]$.

\section{Discussion}

During the last few years the Wnt1-Cre transgenic driver line has proven to be a powerful tool for tissue-specific gene deletion in NCCs $[12,13,27,28]$. Using this approach, several studies have independently shown that the NC-specific deletion of the Tgfbr2 gene leads to a distinct set of calvarial, facial and cardiac defects $[8,9,20,29]$. Interestingly, these defects appear quite different both in the craniofacial and pharyngeal regions, including the heart, when compared to the corresponding mutants of
Alk5, which encodes the TGF- $\beta$ type I receptor, a prototypical binding partner of TGF-ßRII [19] and the present study). While Tgfbr2/Wnt1-Cre mutants as well as mice deficient in Tgf- $\beta 2$ display the PTA type A4 (truncus arteriosus with interrupted aortic arch [30]), Alk5/Wnt1-Cre mutants reported here demonstrate earlier patterning defects of the PAAs, which is particularly obvious in the $3^{\text {rd }}$ pair of the PAAs. Moreover, the Alk5/Wnt1-Cre mutants display an abnormal patterning of the aortic sac and defective AP septation leading to PTA, reminiscent of type A2 (= truncus artriosus with no main pulmonary artery segment present [30]). However, our results also demonstrate that significant hypoplasia of the aortic sac leads to a severe shortening of the ascending truncal arch, which masks possible defects in derivatives of the $4^{\text {th }}$ PAAs, i.e., interruption of the aortic arch. These observed differences are likely due to substantial apoptosis of Alk5deficient post-migratory neural crest cells, which is clearly 


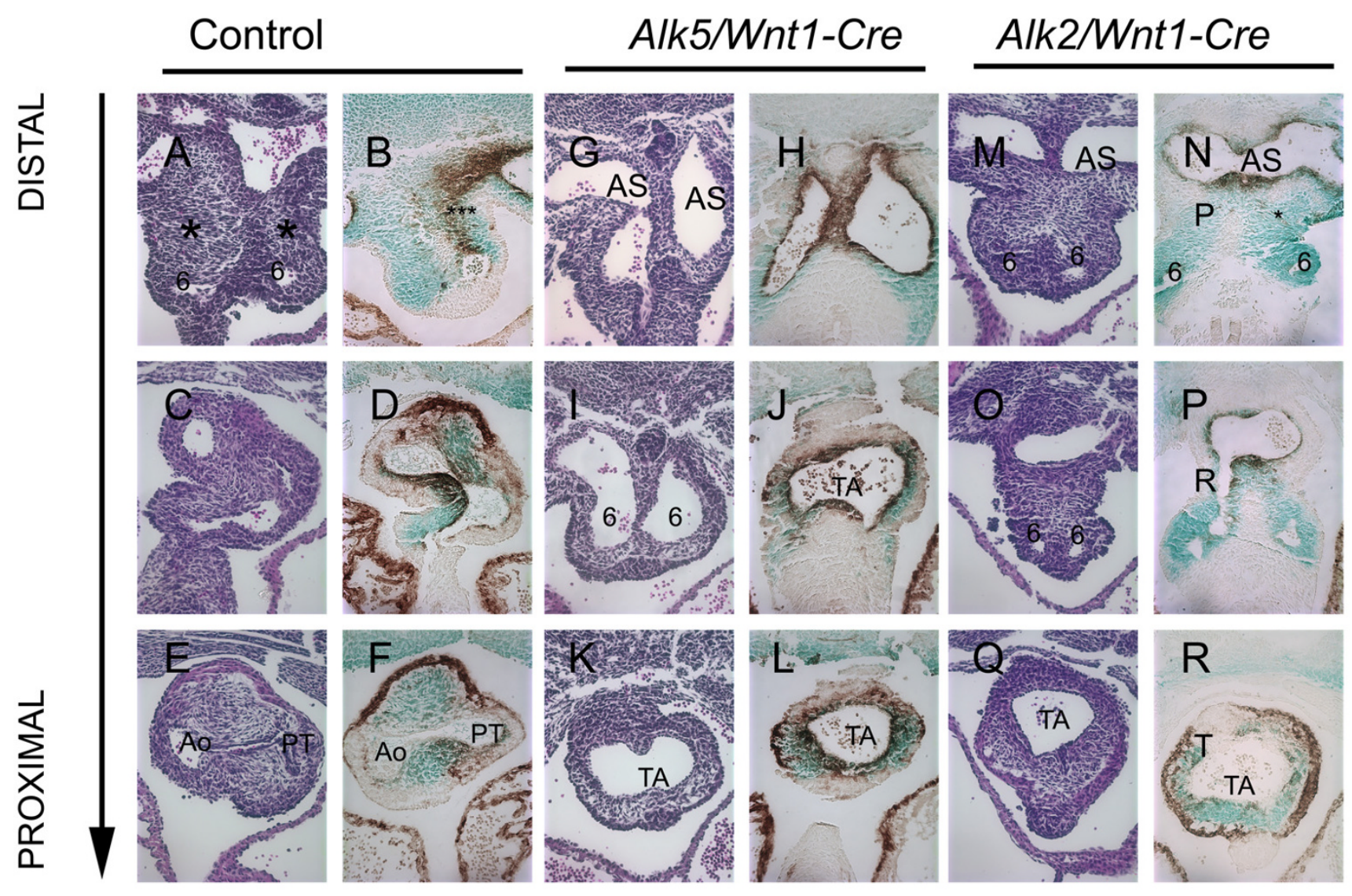

Figure 6

Signaling via ALK5 and ALK2 controls different aspects of aortico-pulmonary septation. Frontal sections from distal (top row) to proximal (bottom row) of the control (A-F), Alk5/Wnt I-Cre mutant (G-L) and Alk2/Wnt I-Cre mutant (M-R) samples (EI I.5). A, C, E, G, I, K, M, O, Q, H\&E staining; B, D, F, H, J, L, N, P, R, double staining for $\alpha$ SMA (brown) and $\beta$-galactosidase (green; R26R reporter assay). 6, the $6^{\text {th }}$ PAA; AS, aortic sac; TA, truncus arteriosus; Ao, Aorta; PT, pulmonary trunk; Asterisks in $A, B, M$ and $N$ depict the AP septal mesenchyme.

detectable at E10.5, whereas similar intense cell death has not been reported in Tgfbr2/Wnt1-Cre mutants[9].

Our present results suggest that while TGF- $\beta$ signaling in cardiac NCCs is predominantly mediated via the ALK5/ TGF- $\beta$ RII receptor complex, ALK5 also mediates signaling of other related ligands, which are either directly or indirectly required for appropriate NCC survival. In fact, it has been shown that, besides TGF- $\beta$ RII, ALK 5 can also form a complex with the Activin type IIB receptor to activate downstream Smads 2/3 [18,31]. Furthermore, a subset of TGF- $\beta$-related growth and differentiation factors (GDFs), e.g., GDF8, GDF9, GDF11 and GDF15 could induce these events [17,18,32,33]. Although relevant Gdfs 8, 911 and 15 are not expressed in the developing heart, nor do the mice deficient in these $G d f s$ display developmental cardiac defects, we cannot exclude the possibility that circulating GDFs, perhaps in concert with TGF- $\beta$ s may contribute to
NCC survival during cardiac and pharyngeal morphogenesis.

We specifically studied apoptosis at the level of the aortic sac, where the AP-septum forms between the origins of $4^{\text {th }}$ and $6^{\text {th }}$ PAAs. Already at E10.5, we could see intense apoptosis among the postmigratory NCCs in the mesenchyme surrounding the aortic sac at the site where the prospective AP septum forms, i.e., this cell death precedes the AP septal defect seen in mutants. Although some NC-derived cells appeared to be differentiating to smooth muscle cells in the OFT (Fig. 6), we could never detect the AP septum forming in Alk5/Wnt1-Cre mutants between E10.5 and E11.5. These findings suggest that the pool of cells forming the AP septum is severely affected by the cell death. Moreover, it is likely that these cells forming the AP-septum die the before majority of them can differentiate to smooth muscle cells. 


\section{Control}
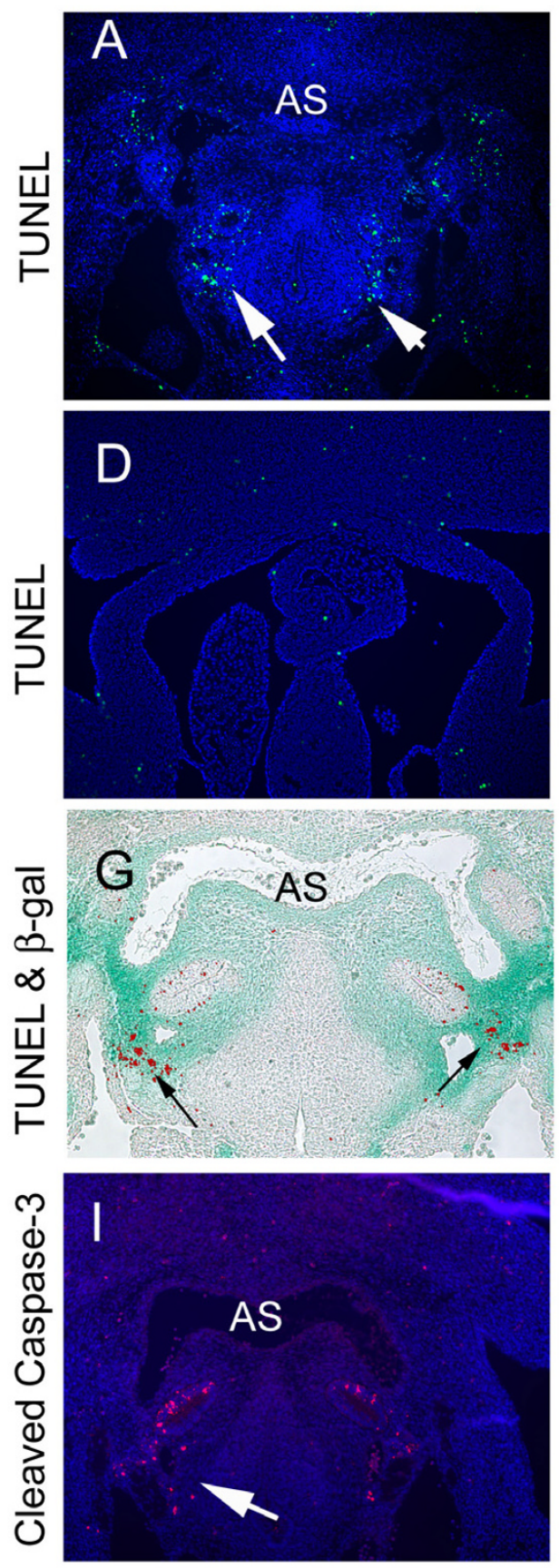

Alk5/Wnt1-Cre
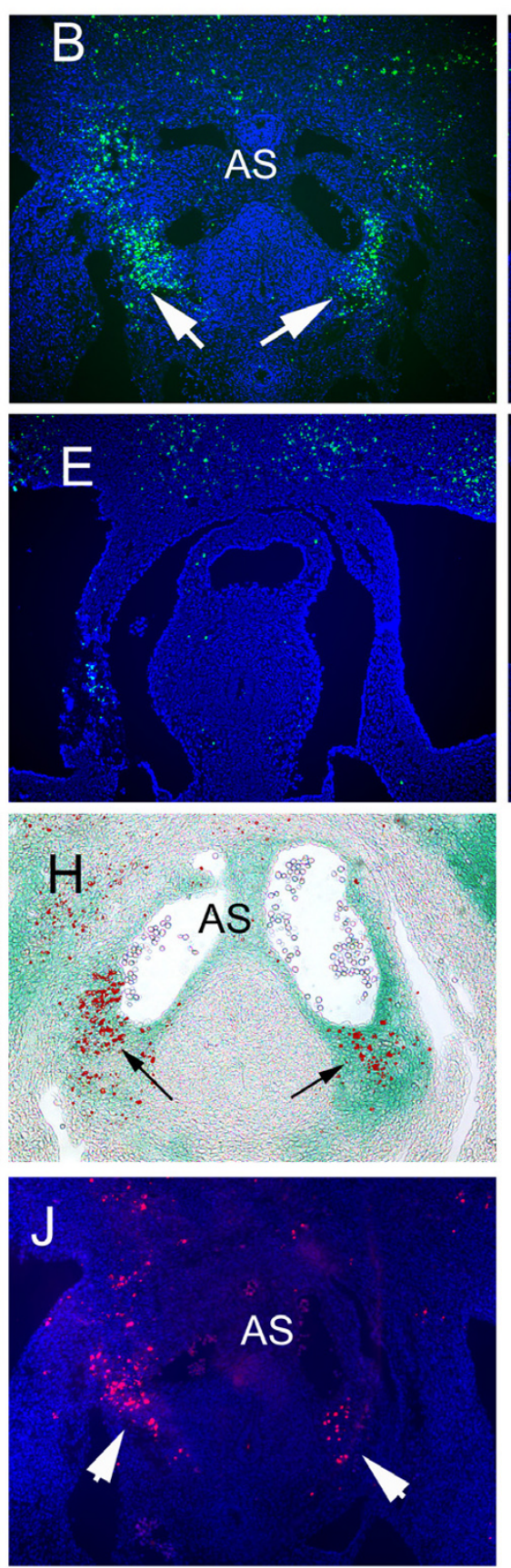

Alk2/Wnt1-Cre
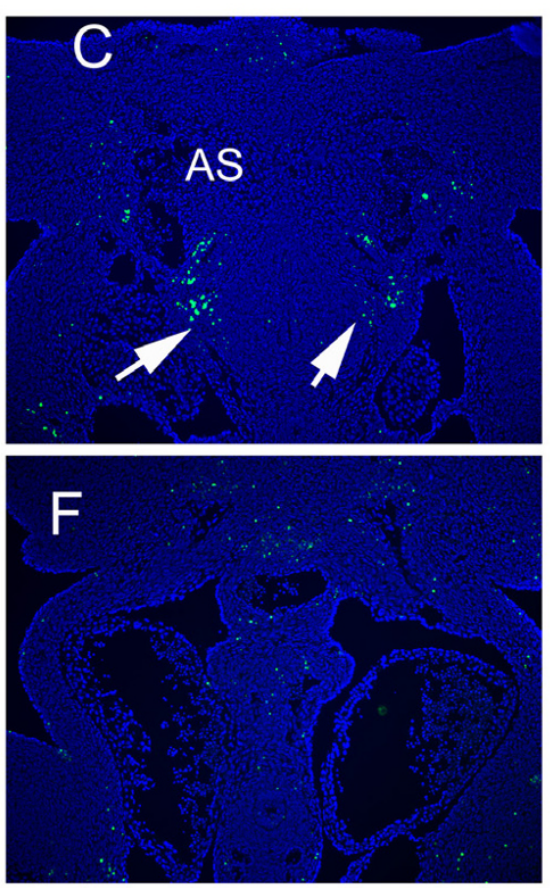

\section{Figure 7}

Aberrant apoptosis of NCCs in Alk5/Wnt I-Cre mutants. TUNEL (A-H) and Cleaved Caspase-3 (I, J) staining at EII.0 demonstrates a notable increase in apoptosis in Alk5/Wnt I-Cre mutants $(\mathrm{B}, \mathrm{H}, \mathrm{J})$ on the aortic sac level when compared to controls (A, G, I) or Alk2/Wnt I-Cre mutants (C) (frontal sections), while sections on the OFT level do not demonstrate differences between controls $(\mathrm{D})$ and Alk5 $(\mathrm{E})$ or Alk2 (F) mutants. G,H, TUNEL staining of lacZ-stained embryos demonstrates that apoptotic cells are of neural crest origin. $\mathrm{G}$, control; $\mathrm{H}$, mutant. AS, aortic sac, arrows point to clusters of apoptotic cells surrounding the aortic sac. 


\section{Control}
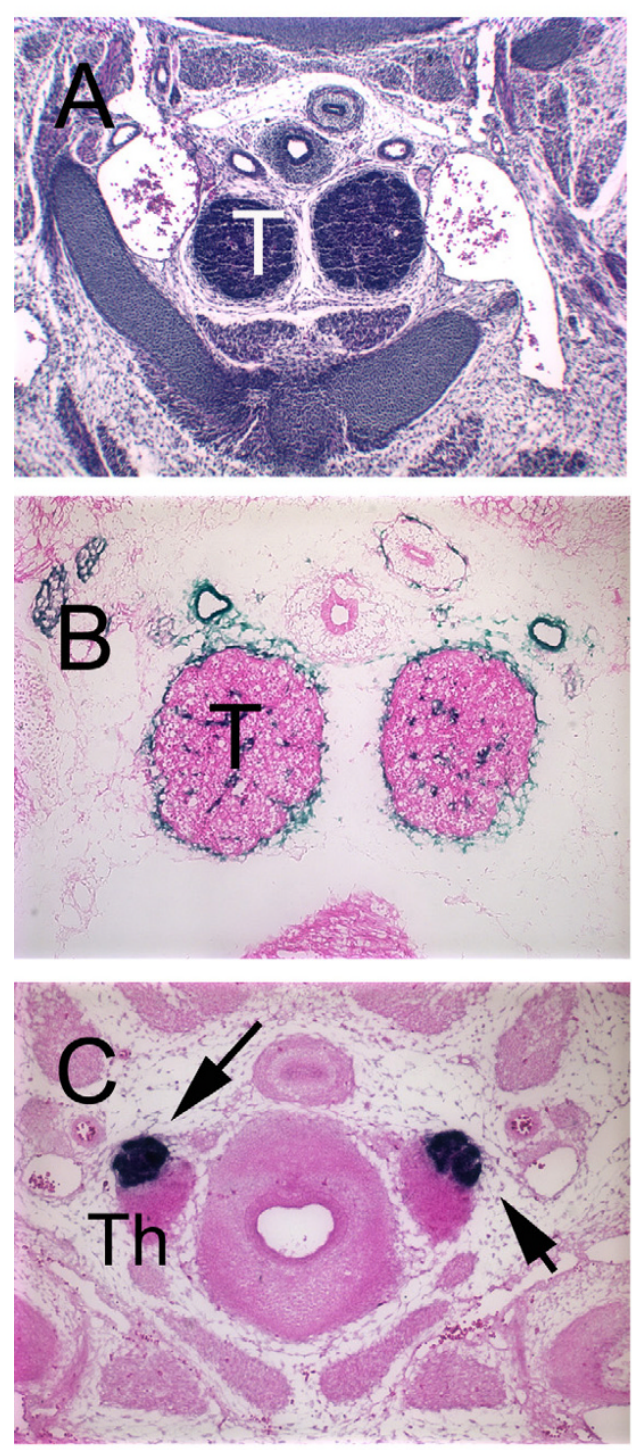

\section{Alk5/Wnt1-Cre}
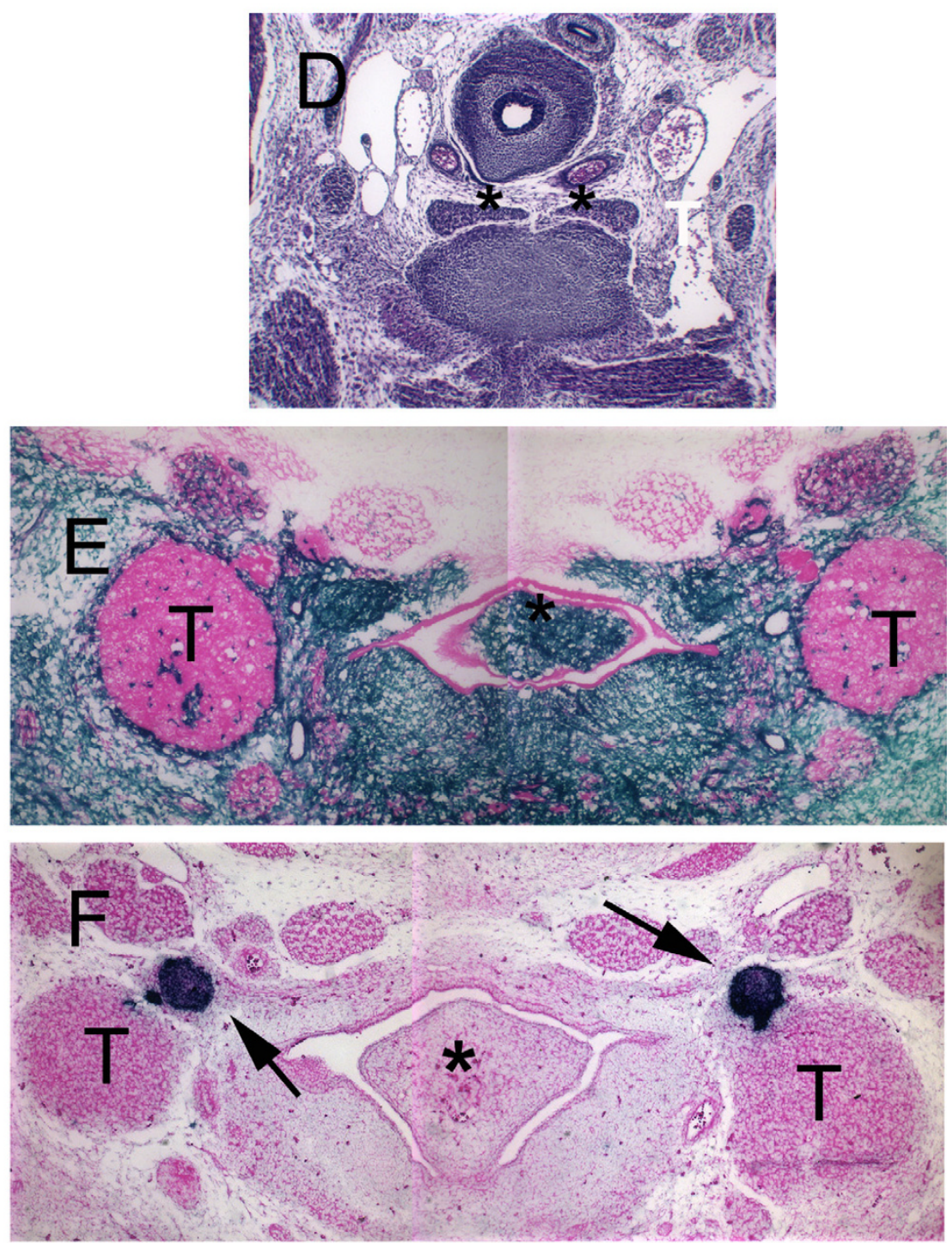

\section{Figure 8}

Pharyngeal organs fail to migrate in Alk5/Wnt I-Cre mutants. At El4.0, the thymus was not detectable in the superior mediastinum (asterisks) in Alk5 mutants (D), when compared to controls (A). Serial sectioning revealed that the thymic primordia had failed to descend and were seen bilaterally in the upper pharyngeal region (E, F) surrounded by neural crest derived mesenchyme (blue staining cells in E). In controls, the parathyroid glands were properly associated with the thyroid glands (arrows in C), while in Alk5 mutants the parathyroid glands were associated with the thymic primordia (arrows in F). However, both controls and mutants expressed parathyroid hormone (PTH) at comparable levels (blue staining in $C$ and F). A and D, hematoxyllin and eosin staining; B and E, R26 R lineage tracing assay - counterstaining with eosin; $C$ and $F$, section in situ hybridization for PTH - counterstaining with eosin. T, thymus; Th, thyroid; asterisks in D depict the absence of the thymic primordia; asterisks in $\mathrm{E}$ and $\mathrm{F}$ depict the tongue. 
Several in vitro studies have suggested an indispensable role for TGF- $\beta$-signaling in differentiation of NCCs into smooth muscle cells. Moreover, a recent in vivo study suggested that mice lacking Tgfbr2 in CNCCs display defective NCC differentiation into $\alpha$ SMA-positive cells in the AP septum [9], although this result was later disputed by another study [8]. Our immunohistochemical staining of $\alpha \mathrm{SMA}$ in the OFT unequivocally demonstrated that signaling via ALK5 is not required for smooth muscle differentiation in vivo. Moreover, it has been suggested that deletion of Tgfbr2 in NCCs leads to other phenotypic features reminiscent of those seen in the velocardiofacial/ DiGeorge syndrome (VCF/DGS) [9] caused by a deletion of the so called DiGeorge critical region (DGCR) on chromosome 22q11 [34,35]. Our present results suggest that although many of the observed phenotypes seen in Alk5/ Wnt1-Cre mutants superficially resemble those seen in VCF/DGS, a detailed examination shows that the NC-specific abrogation of Alk5 does not lead to VCF/DGS-like phenotypes. Firstly, while the pharyngeal organ migration fails in Alk5/Wnt1-Cre mutants, perhaps as a result of increased mesenchymal cell death in the pharyngeal region, both the thymus, thyroid and parathyroid seem to develop relatively normally on the histological level in these mutants. Secondly, the NCC death seen in Alk5 mutants affects a predominantly postmigratory population of NCCs, while genes located in the DGCR, i.e., $T b x 1$ and CrkL, control NCC survival earlier at E8.5-E10 by regulating proliferation of the secondary heart field (SHF), and endoderm expansion, which in turn provides survival signal for NCCs allowing them to populate the pharyngeal region [36-39].

NCC ablation in the chick has been shown to lead to PTA and to a failure of addition of myocardium from the secondary heart field [40]. It was suggested that the defective migration of cells from the secondary heart field to the OFT in turn resulted in shortening and inappropriate rotation of the OFT, leading to mal-alignment of the arterial pole with the ventricles [41]. While the detected OFT phenotype in Alk5/Wnt1-Cre mutants shared many similarities with that seen in the chick NC ablation models, e.g., PTA and the hypoplastic aortic sac, our current results suggest that the secondary heart field is not severely affected in Alk5 mutants (data not shown). Since we could not detect appropriate rotation of the OFT in neural crest-specific mutants of Alk5 or Alk2, it appears that cells derived from the $\mathrm{NC}$, as well as those from the SHF, are mutually required for proper OFT rotation in mice. However, it appears that these two TGF- $\beta$ /BMP type I receptors contribute to OFT rotation through different mechanisms. In Alk5 mutants there is very little, if any, detectable septal mesenchyme present, and thus it could be argued that in these mutants OFT rotation fails due to a lack of penetration of septal prongs into the cushion mesenchyme. In contrast, in Alk2/Wnt1-Cre mutants a sizeable septal mesenchyme could be seen, still without any obvious looping of the aortic sac and truncal OFT, suggesting that the mere presence of the septal mesenchyme, without correct smooth muscle cell differentiation, is not sufficient for OFT rotation.

\section{Conclusion}

In this study, we have deleted the TGF- $\beta$ type I receptor (Alk5) gene specifically in the mouse neural crest (NC) cell lineage. Our data suggest that ALK5 is required cell autonomously in the NC to mediate non-redundant signaling events that are essential for appropriate patterning of the pharyngeal organs and cardiac OFT. The cardiac and pharyngeal defects observed in the NC-specific Alk5 mutants differ significantly from those seen in corresponding mutants lacking the TGF- $\beta$ type II receptor, suggesting that signaling mediated by ALK5 is not limited to the classical TGF- $\beta$ ligands during cardiac/pharyngeal development.

\section{Methods \\ Alk5/Wnt ICre mice}

Alk5 (and Alk2) mutant and control embryos were generated by mating Alk5ko/+ $\left(\right.$ Alk2 $\left.{ }^{\mathrm{ko} /+}\right) /$ Wnt1-Cre male mice with females homozygous for the Alk5 flox (Alk2 flox) allele and the R26R reporter $[12,19]$. Genotyping was performed by PCR as described earlier [21,42]. Wnt1-Cre mice were kindly provided by A. McMahon (Harvard University) and R26R reporter mice were obtained from the Jackson laboratories. All studies were carried out at the Animal Care Facility of the Saban Research Institute of Childrens Hospital Los Angeles in accordance with institutional guidelines.

\section{Timed mataings}

Mice were mated during the dark period of the controlled light cycle; presence of vaginal plugs was designated as day 0 hour 0 . Females were euthanized by $\mathrm{CO}_{2}$, and embryos were collected in Hanks' balanced salt solution on ice.

\section{Histological analyses}

Embryos (E17) were fixed with 4\% paraformaldehyhe for 14 hours, dehydrated and embedded in paraffin wax. Sections (7-8 um) were stained with Hematoxylin and Eosin ( $n \geq 3$ for each genotype). For lineage tracing analyses, embryos were stained for $\beta$-galactosidase activity as described [43]. Briefly, the specimens (E11.0 - E11.5) were fixed in $4 \%$ paraformaldehyde for 30 minutes at room temperature, washed 3 times for 10 minutes in the detergent wash and developed for 2-12 hours in X-gal solution ( $\mathrm{n} \geq 3$ for each genotype). For immunohistochemistry, fixed sections from tissues harvested at E10.5 E11.5 were stained with monoclonal $\alpha$-smooth muscle 
actin (DAKO), cleaved caspase-3 (Cell Signaling) or phophohistone-H3 (Cell Signaling) antibodies. TUNEL assays were performed using the DeadEnd fluorometric TUNEL system (Promega). In each assay 3 or more embryos were analyzed for each genotype.

\section{Ink and casting dye injections}

Embryos (E10.0 - E13.0) were dissected and placed in ice cold PBS ( $\mathrm{n} \geq 3$ per genotype in each time point). Using a pulled glass pipette, India ink or Yellow casting dye (Connecticut Valley Biological Supply) was injected into the ventricles until ink/dye penetrated small vessels. Embryos were postfixed in $10 \%$ buffered formalin for 12 hours, dehydrated and cleared in benzylbenzoate: benzyl alcohol $(2: 1 \mathrm{v} / \mathrm{v})$.

\section{Expression analyses}

To visualize parathyroid hormone expression we used in situ hybridization and an antisense probe corresponding to nucleotides 97-534 (kindly provided by Nancy Manley) as described [44].

\section{Authors' contributions}

J.W. did most of the mouse dissections and analyses, A.N. did some of the histological analyses, J.L. generated the

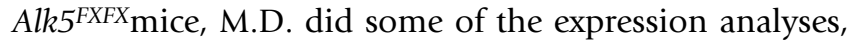
H.M.S. participated in design and provided the Tgfbr2 mutant embryos and V.K. generated the Alk2 ${ }^{\text {FXFX }}$ mice, designed and supervised the experiments and wrote the manuscript. All authors have read and approved the final manuscript.

\section{Acknowledgements}

We thank A. McMahon for providing the Wnt I-Cre mouse line, N. Manley for the PTH probe and B. Choudhary for Tgfbr2/Wnt I-Cre embryos. H.M.S. was supported by grants from the $\mathrm{NIH}$, and V.K. by grants from the Robert E. Schneider Foundation and the NIH (HL074862 and DEO I 3085).

\section{References}

I. Kirby ML, Gale TF, Stewart DE: Neural crest cells contribute to normal aorticopulmonary septation. Science 1983, 220:1059-106I.

2. Kirby ML, Waldo KL: Neural crest and cardiovascular patterning. Circ Res 1995, 77:21 I-2I5.

3. LaBonne C, Bronner-Fraser M: Molecular mechanisms of neural crest formation. Annu Rev Cell Dev Biol 1999, I 5:8 I-I I 2.:8I-I I 2 .

4. Jiang $X$, Rowitch DH, Soriano P, McMahon AP, Sucov HM: Fate of the mammalian cardiac neural crest. Development 2000, 127:1607-1616.

5. Hutson MR, Kirby ML: Neural crest and cardiovascular development: a 20-year perspective. Birth Defects Res C Embryo Today 2003, 69:2-13.

6. LeDouarin: The Neural Crest cambridge, Cambridge University Press; 1982.

7. Molin DG, DeRuiter MC, Wisse LJ, Azhar M, Doetschman T, Poelmann RE, Gittenberger-de Groot AC: Altered apoptosis pattern during pharyngeal arch artery remodelling is associated with aortic arch malformations in Tgfbeta2 knock-out mice. Cardiovasc Res 2002, 56:3 I2-322.

8. Choudhary B, Ito Y, Makita T, Sasaki T, Chai Y, Sucov HM: Cardiovascular malformations with normal smooth muscle differ- entiation in neural crest-specific type II TGFbeta receptor (Tgfbr2) mutant mice. Dev Biol 2006, 289:420-429.

9. Wurdak H, Ittner LM, Lang KS, Leveen P, Suter U, Fischer JA, Karlsson S, Born W, Sommer L: Inactivation of TGFbeta signaling in neural crest stem cells leads to multiple defects reminiscent of DiGeorge syndrome. Genes Dev 2005, 19:530-535.

10. Kim RY, Robertson EJ, Solloway MJ: Bmp6 and Bmp7 are required for cushion formation and septation in the developing mouse heart. Dev Biol 200I, 235:449-466.

II. Delot EC, Bahamonde ME, Zhao M, Lyons KM: BMP signaling is required for septation of the outflow tract of the mammalian heart. Development 2003, 130:209-220.

12. Kaartinen V, Dudas M, Nagy A, Sridurongrit S, Lu MM, Epstein JA: Cardiac outflow tract defects in mice lacking ALK2 in neural crest cells. Development 2004, I 3 I:348 I-3490.

13. Stottmann RW, Choi M, Mishina Y, Meyers EN, Klingensmith J: BMP receptor IA is required in mammalian neural crest cells for development of the cardiac outflow tract and ventricular myocardium. Development 2004, 1 31:2205-22 I8.

14. Derynck R, Feng XH: TGF-beta receptor signaling. Biochim Biophys Acta 1997, I333:FI05-FI50.

15. Shi Y, Massague J: Mechanisms of TGF-beta signaling from cell membrane to the nucleus. Cell 2003, I I 3:685-700.

16. Goumans MJ, Valdimarsdottir G, Itoh S, Lebrin F, Larsson J, Mummery C, Karlsson S, ten Dijke P: Activin receptor-like kinase (ALK) I is an antagonistic mediator of lateral TGFbeta/ALK5 signaling. Mol Cell 2003, I 2:817-828.

17. Rebbapragada A, Benchabane H, Wrana JL, Celeste AJ, Attisano L: Myostatin signals through a transforming growth factor beta-like signaling pathway to block adipogenesis. Mol Cell Biol 2003, 23:7230-7242.

18. Mazerbourg S, Klein C, Roh J, Kaivo-Oja N, Mottershead DG, Korchynskyi O, Ritvos O, Hsueh AJ: Growth differentiation factor-9 signaling is mediated by the type I receptor, activin receptor-like kinase 5. Mol Endocrinol 2004, 1 8:653-665.

19. Dudas M, Kim J, Li WY, Nagy A, Larsson J, Karlsson S, Chai Y, Kaartinen V: Epithelial and ectomesenchymal role of the type I TGF-beta receptor ALK5 during facial morphogenesis and palatal fusion. Dev Biol 2006, 296:298-3/4.

20. Ito Y, Yeo JY, Chytil A, Han J, Bringas P Jr., Nakajima A, Shuler CF, Moses HL, Chai Y: Conditional inactivation of Tgfbr2 in cranial neural crest causes cleft palate and calvaria defects. Development 2003, 130:5269-5280.

21. Larsson J, Goumans MJ, Sjostrand LJ, van Rooijen MA, Ward D, Leveen P, Xu X, ten Dijke P, Mummery CL, Karlsson S: Abnormal angiogenesis but intact hematopoietic potential in TGF-beta type I receptor-deficient mice. EMBO J 200I, 20:1663-1673.

22. Danielian PS, Muccino D, Rowitch DH, Michael SK, McMahon AP: Modification of gene activity in mouse embryos in utero by a tamoxifen- inducible form of Cre recombinase. Curr Biol 1998, 8:1323-1326.

23. Hiruma T, Nakajima $Y$, Nakamura H: Development of pharyngeal arch arteries in early mouse embryo. J Anat 2002, 201:15-29.

24. Waldo K, Miyagawa-Tomita S, Kumiski D, Kirby ML: Cardiac neural crest cells provide new insight into septation of the cardiac outflow tract: aortic sac to ventricular septal closure. Dev Biol 1998, 196:129-144.

25. Poelmann RE, Mikawa T, Gittenberger-de Groot AC: Neural crest cells in outflow tract septation of the embryonic chicken heart: differentiation and apoptosis. Dev Dyn 1998, 21 2:373-384.

26. Keyes WM, Sanders EJ: Regulation of apoptosis in the endocardial cushions of the developing chick heart. Am J Physiol Cell Physiol 2002, 282:CI348-CI360.

27. Tallquist MD, Soriano P: Cell autonomous requirement for PDGFRalpha in populations of cranial and cardiac neural crest cells. Development 2003, |30:507-518.

28. Brault V, Moore R, Kutsch S, Ishibashi M, Rowitch DH, McMahon AP, Sommer L, Boussadia O, Kemler R: Inactivation of the beta-catenin gene by Wntl-Cre-mediated deletion results in dramatic brain malformation and failure of craniofacial development. Development 200I, I 28: I 253-I264.

29. Sasaki T, Ito Y, Bringas P Jr., Chou S, Urata MM, Slavkin H, Chai Y: TGF beta\}-mediated FGF signaling is crucial for regulating cranial neural crest cell proliferation during frontal bone development. Development 2006, 133:37I-38I. 
30. Jacobs ML: Congenital Heart Surgery Nomenclature and Database Project: truncus arteriosus. Ann Thorac Surg 2000, 69:S50-S55.

31. Oh SP, Yeo CY, Lee Y, Schrewe H, Whitman M, Li E: Activin type IIA and IIB receptors mediate GdfI I signaling in axial vertebral patterning. Genes Dev 2002, 16:2749-2754.

32. Xu J, Kimball TR, Lorenz JN, Brown DA, Bauskin AR, Klevitsky R, Hewett TE, Breit SN, Molkentin JD: GDFI 5/MIC-I functions as a protective and antihypertrophic factor released from the myocardium in association with SMAD protein activation. Circ Res 2006, 98:342-350.

33. Ge G, Hopkins DR, Ho WB, Greenspan DS: GDFI I forms a bone morphogenetic protein I-activated latent complex that can modulate nerve growth factor-induced differentiation of PCI 2 cells. Mol Cell Biol 2005, 25:5846-5858.

34. McDermid HE, Morrow BE: Genomic disorders on 22qI I. Am J Hum Genet 2002, 70:1077-1088.

35. Epstein JA: Developing models of DiGeorge syndrome. Trends Genet 200I, I7:SI3-SI7.

36. $\mathrm{Xu} \mathrm{H}$, Cerrato $\mathrm{F}$, Baldini $\mathrm{A}$ : Timed mutation and cell-fate mapping reveal reiterated roles of TbxI during embryogenesis, and a crucial function during segmentation of the pharyngeal system via regulation of endoderm expansion. Development 2005, 132:4387-4395.

37. Xu H, Morishima M, Wylie JN, Schwartz RJ, Bruneau BG, Lindsay EA, Baldini A: Tbxl has a dual role in the morphogenesis of the cardiac outflow tract. Development 2004, I 3 I:32 I7-3227.

38. Moon AM, Guris DL, Seo JH, Li L, Hammond J, Talbot A, Imamoto A: Crkl deficiency disrupts Fgf8 signaling in a mouse model of 22q I I deletion syndromes. Dev Cell 2006, 10:7I-80.

39. Zhang Z, Cerrato F, Xu H, Vitelli F, Morishima M, Vincentz J, Furuta Y, Ma L, Martin JF, Baldini A, Lindsay E: Tbx I expression in pharyngeal epithelia is necessary for pharyngeal arch artery development. Development 2005, 132:5307-5315.

40. Ward C, Stadt H, Hutson M, Kirby ML: Ablation of the secondary heart field leads to tetralogy of Fallot and pulmonary atresia. Dev Biol 2005, 284:72-83.

4I. Hutson MR, Zhang P, Stadt HA, Sato AK, Li YX, Burch J, Creazzo TL, Kirby ML: Cardiac arterial pole alignment is sensitive to FGF8 signaling in the pharynx. Dev Biol 2006, 295:486-497.

42. Dudas M, Sridurongrit S, Nagy A, Okazaki K, Kaartinen V: Craniofacial defects in mice lacking BMP type I receptor Alk2 in neural crest cells. Mech Dev 2004, I 2 I: 173- 82.

43. Hogan B, Beddington R, Costantini F, Lacy E: Manipulating the mouse embryo. A laboratory manual 2nd edition. Edited by: Hogan B, Beddington R, Costantini F and Lacy E. New York, Cold Spring Harbor Laboratory Press; 1994.

44. Moorman AF, Houweling AC, de Boer PA, Christoffels VM: Sensitive nonradioactive detection of mRNA in tissue sections: novel application of the whole-mount in situ hybridization protocol. J Histochem Cytochem 200I, 49: I-8.

Publish with Bio Med Central and every scientist can read your work free of charge

"BioMed Central will be the most significant development for disseminating the results of biomedical research in our lifetime. "

Sir Paul Nurse, Cancer Research UK

Your research papers will be:

- available free of charge to the entire biomedical community

- peer reviewed and published immediately upon acceptance

- cited in PubMed and archived on PubMed Central

- yours - you keep the copyright

Submit your manuscript here:

http://www.biomedcentral.com/info/publishing_adv.asp
BioMedcentral 